\title{
O GUIA DE TURISMO: UMA ABORDAGEM LEGAL SOBRE UMA PROFISSÃO NO BRASIL
}

THE TOUR GUIDE: A LEGAL APPROACH ON THIS PROFESSION IN BRAZIL

EL GUÍA DE TURISMO: UN ENFOQUE JURÍDICO A UNA PROFESIÓN EN BRASIL

Gabriel Dunchatt Zettermann

Universidade Federal de Santa Catarina

Mestrando em Ergonomia, Especialização em Engenharia de Segurança do Trabalho e Graduação em Engenharia de Produção gabriel.zettermann@yahoo.com.br

\section{Lizandra Garcia Lupi Vergara}

Universidade Federal de Santa Catarina

Doutora e Mestre em Ergonomia e Graduação em Arquitetura e Urbanismo

I.vergara@ufsc.br

Data de Submissão: 12/04/2016

Data de aprovação: 11/10/2016

RESUMO: Pela escassez de estudos publicados referentes à relação do guia de turismo e a legislação brasileira, o objetivo desse estudo foi de identificar, por meio de uma abordagem legal, a situação do guia de turismo no Brasil. Buscando nas legislações relacionadas à profissão, preenchimento de lacunas sobre questões legais referentes aos seus direitos ou a inexistência deles. Refere-se a um estudo exploratório, por meio de uma pesquisa bibliográfica e documental. Como resultado, o guia de turismo é reconhecido e regulamentado na legislação brasileira, determinando direitos, deveres e obrigações em normas fundamentais, supralegais, ordinárias, regulamentadoras e infralegais (coletivas e individuais). Pelo qual, possibilita uma liberdade de escolha sobre a sua relação de trabalho, influenciando nas questões referentes sobre seus direitos trabalhistas.

PALAVRAS-CHAVES: Guia de Turismo, Legislação Brasileira, Direitos Trabalhistas.

ABSTRACT: The scarcity of published studies on the relationship between the tour guide and the Brazilian legislation, the purpose of the study was to identify, through a legal approach, the situation 
of tour guide in Brazil. Seeking the laws related to the profession, gap-filling on legal issues relating to their rights or the lack of them. It refers to an exploratory study, through a bibliographic and documentary research. As a result, the tour guide is recognized and regulated by Brazilian law, determining rights, duties and obligations As a result, the tour guide is recognized and regulated by Brazilian law, determining rights, duties and obligations on basic, supralegal, common, regulatory and infralegal (collective and individual) norms. At which enables freedom of choice about their working relationship, influencing the related questions about their labor rights.

KEYWORDS: Tour Guide, Brazilian Legislation, Labor Rights.

RESUMEN: Por la escasez de estudios publicados sobre la relación de la guía y la legislación brasileña, el objetivo del estudio fue identificar, a través de un enfoque jurídico, la situación del guía de turismo en Brasil. Buscando las leyes relacionadas con la profesión, brecha llenars en temas legales relacionados con sus derechos o la falta de ellos. Se refiere a un estudio exploratorio, a través de una investigación bibliográfica y documental. Como resultado, el guía es reconocida y regulada por la ley brasileña, la determinación de los derechos, deberes y obligaciones reglas fundamentales, supralegais, ordinarias, de regulación y infralegales (colectivos e individuales). En lo que permite la libertad de elección acerca de su relación de trabajo, que influyen en las preguntas relacionadas acerca de sus derechos laborales.

PALABRAS CLAVE: Guía de turismo, La legislación brasileña, Los derechos laborales.

\section{INTRODUÇÃO}

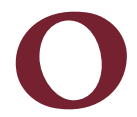

guia de turismo pode ser definido como "um profissional polivalente" (Trigo, 2009, p. 73), "que faz a adequação entre o turista e a comunidade visitada" (Valle, 2004, p. 82), com a responsabilidade de iniciar, desenvolver e finalizar um passeio turístico. Possui a capacidade e oportunidade de promover os recursos e atrações turísticas da localidade.

Esse profissional atua tanto no turismo receptivo (quando não residentes são recebido no destino) quanto no emissivo (quando residentes viajam para o destino), em translado, city tours e excursões. Utilizando ônibus, avião ou qualquer outro meio de transporte. Tem a responsabilidade, segundo Trigo (2009), de garantir que os serviços contratados (transporte, hospedagem, restaurantes, entre outros) sejam cumpridos; e de lidar com situações que possam acontecer dentro do grupo, como: desentendimentos, adoecimentos, acidentes, extravio ou furto de bagagens, perda de documentos e preocupações relacionados à segurança.

Capaz de eliminar as inseguranças que possam existir, o guia de turismo é um mediador entre aqueles que buscam conhecer alguma coisa e o local ainda 
desconhecido, interagindo com diversas pessoas (turistas, habitantes locais, prestadores de serviços, entre outros) e indicando lugares de interesse turísticos. Garantindo para os turistas as melhores experiências, momentos, impressões e lembranças. Simplesmente, "um turista não só vê pontos turísticos locais a partir do isolamento físico de um ônibus, mas interpreta as vistas por meio das palavras do guia de turismo" (Schmidt, 1979, p. 446, tradução livre).

Por sua vez, uma legislação ou o processo legislativo é fundamental para o exercício da cidadania e de uma profissão. Foram feitas para contribuir com a organização na sociedade, em que todos tenham direitos, deveres e obrigações a serem respeitados. Contudo, é formada por leis ou normas jurídicas, normas de condutas "no sentido que seu escopo direto ou indireto é dirigir o comportamento dos indivíduos particulares, comunidades, dos governantes e funcionários no seio do Estado e do mesmo Estado na ordem internacional" (Diniz, 2012, p. 41).

Porém, não existem muitos estudos publicados referentes à relação do guia de turismo e a legislação brasileira. Valle (2004), um desses poucos estudos, buscou obter uma perspectiva globalizante desse profissional no contexto atual, referenciando sobre os instrumentos legais que regulam profissão de guia de turismo. Diagnosticando que:

A legislação brasileira, apesar de ser uma das mais complexas, apresenta um emaranhado de leis, decretos e resoluções falhas, com contradições e sobreposições. É como se as instituições brasileiras tivessem percebido, em determinado momento, a importância do guia de turismo e tivessem começado a criar normatizações sem uma análise complexa da legislação vigente, nem do envolvimento das mesmas (p. 84).

Enquanto, Julião, Cortês, Farias, Lohmart e Silva (2009), outro desses poucos estudos, propuseram construir um debate teórico que relacione as leis trabalhistas com a legislação do turismo, cujo foco eram as questões trabalhistas que envolvam esse profissional. Como resultado, inferiram:

Com base na análise dos aspectos da relação entre trabalho e capital e na perspectiva do guia de turismo, como profissão regulamentada, reconhecida e com sindicato próprio, que, mesmo nessas condições, não existe garantia dos direitos trabalhistas; ao contrário, encontra-se 

um mercado de trabalho regido pela lógica da flexibilização (p. 17).

Diante disso, o objetivo do estudo foi de identificar, por meio de uma abordagem legal, a situação do guia de turismo no Brasil. Buscando, nas legislações relacionadas à profissão, o preenchimento de lacunas sobre questões legais referentes aos seus direitos ou a inexistência deles.

\section{ORDENAMENTO JURÍDICO E O PROCESSO LEGISLATIVO NO BRASIL}

Ordenamento jurídico pode ser definido, segundo Mota (2012), com uma integralização lógica das normas que compõe de diversas fontes dos poderes executivos, legislativos ou jurídicos, pelo qual desenvolve uma hierarquia. Enquanto, o "processo legislativo" é uma expressão que, segundo Paulo e Alexandrino (2008, p. 463), "compreende o conjunto de atos realizados pelos órgãos competentes na produção das leis e outras espécies normativas indicadas diretamente pela Constituição".

Por sua vez, as leis ou normas jurídicas produzidas têm a função de manter a organização na sociedade, o não cumprimento delas impõe penalidades em prol de um bem maior. Segundo Cunha (2010), o conjunto de normas jurídicas regula a conduta humana na sociedade, sua violação prescrevera uma sanção, exigindo que seus violadores uma reparação do mal causado (Telles Junior, 2008).

A constituição é a lei fundamental e suprema de uma região, país ou nação, possui normas que constituem a formação dos poderes públicos, garantindo os direitos e deveres dos cidadãos. Para Poletti (2010, p. 216) Dé um corolário do princípio da legalidade aplicado nos países de Constituição escritaロ. Ela, segundo Lenza (2012), é formada por texto com regras que limitam o poder autoritário e determina os direitos fundamentais para uma sociedade.

No Brasil, o ponto de partida quando tratamos de leis, é a Constituição Federal de 1988, que é a principal norma jurídica do País. É nele que estão disponíveis os direitos, deveres e obrigações de todos os cidadãos brasileiros, como: o direito à vida, liberdade, igualdade, trabalho, educação, saúde, alimentação, moradia, transporte, lazer, segurança e dignidade. 
Após a Constituição Federal, de acordo com Paulo e Alexandrino (2008), Mota (2012), Lenza (2012), Ferraz Junior (2015) e Tavares (2016), a legislação brasileira, sobre os atos normativos ou normas jurídicas, segue a seguinte hierarquia ou ordenamento jurídico:

1. Fundamentais:

- Emendas constitucionais - tem o poder de acrescentar, modificar ou suspender artigos da Constituição; e

- Leis complementares - tem o propósito de complementar, explicar ou adicionar algo à Constituição.

2. Supralegais:

- Tratados e Convenções Internacionais de Direitos Humanos providos pelas relações entre o Brasil com outros países e sua participação em organizações internacionais.

3. Ordinárias:

- Códigos - conjuntos de normas estabelecidos por lei ordinária, uma regulação unitária de um ramo do direito;

- Leis ordinárias - são compostas por regras e normas gerais elaboradas pelo Poder Legislativo;

- Leis delegadas - são regras e normas gerais elaboradas pelo Presidente da República e repassadas para o Poder Legislativo;

- Medidas provisórias - processo de elaboração normativa ao lado da lei, editado pelo Presidente da República;

- Decreto-Lei - substituído pelas medidas provisórias na Constituição Federal de 1988, consistia em um decreto com força de lei elaborado pelo Presidente da República;

- Decretos legislativos - elaborados pelo Congresso Nacional, com a finalidade de tratar as matérias da sua competência exclusiva, dispensando a sanção presidencial; e 
- Resoluções - são deliberações utilizadas pelo Congresso Nacional, para dispor sobre assuntos políticos e administrativos de sua competência, que não estejam sujeitos à reserva de lei.

4. Regulamentadoras:

- Decretos regulamentares - são normas jurídicas gerais, meramente administrativas estabelecidas pelo Presidente da República, para desenvolver uma lei, facilitando sua execução; e

- Portarias - um documento de ato jurídico vindo do Poder Executivo, que contém ordens e instruções acerca da aplicação de leis, decretos, recomendações de caráter geral e normas sobre a execução de serviços.

5. Infralegais:

- Normas coletivas - instruções normativas, resoluções normativas, deliberações normativas, acordo coletivo de trabalho, convenção coletiva de trabalho, regimentos, estatutos e outros;

- Normas individuais - contratos, sentenças judiciais, testamentos e outros.

Alguns autores descreveram que não há uma diferença de hierarquia entre a lei complementar e as ordinárias, apenas as competências são diferentes sem qualquer tipo de relação. Ferraz Junior (2015) afirmou que não há hierarquia entre elas, e sim uma exigência que cada qual fique em seu âmbito e não invada o outro. Já Diniz (2012) acredita que lei complementar está entre a Constituição e as leis ordinárias. Simplesmente, porque a lei complementar está relacionada diretamente com uma lei fundamental e suprema.

Para Paulo e Alexandrino (2008) não existem hierarquia entre as normas primárias, com a exceção das emendas constitucionais. As normas primárias são atos normativos diretamente fundamentados na própria Constituição Federal de 1988, previstos no Art. 59, como: a emenda constitucional (Art. 60), leis complementares (Art. 69), leis ordinárias (Art. 47), leis delegadas (Art. 68), medidas provisórias (Art. 62), decretos legislativos (Art. 49) e resoluções (Art. 51,52 e 68). 
Enquanto, no Art. $5^{\circ}$ da Constituição Federal de 1988, determina que os tratados e convenções internacionais de direitos humanos aprovados no Congresso Nacional serão equivalentes às emendas constitucionais. Enquanto isso, outros tipos de tratados e convenções internacionais poderão ter o mesmo valor de normas jurídicas ordinárias ou regulamentadoras (Lenza, 2012).

Por fim, segundo Mota (2012), atos normativos com a finalidade de regulamentação de normas primárias, são considerados atos de natureza administrativa, sendo assim são inferiores as leis fundamentais, aos supralegais e ordinários. O mesmo serve com as normas coletivas e individuais, que é o último grau de hierarquia das normas jurídicas.

No entanto, o Brasil é formado por 26 Estados e um Distrito Federal, compostos por diversos municípios, no qual cada um tem o seu processo legislativo semelhante à do País. Segundo Lenza (2012), todos os Estados possuem uma constituição própria tendo simetria constitucional com a Constituição Federal, enquanto os municípios e o Distrito Federal são as leis orgânicas que as regem.

As leis federais, estaduais, municipais ou do Distrito Federal, sejam de que espécie for (complementares, ordinárias, delegadas) não possuem uma hierarquia, o que existe é competência jurídica em seu âmbito de atuação. Para Ferraz Junior (2015), lei federal não prevalece sobre a estadual e nem municipal, por pertencerem a âmbitos diferentes. Já Paulo e Alexandrino (2008, p. 534) descrevem que:

Uma lei federal só será válida se estiver no seu âmbito de atuação, traçado na Constituição Federal; uma lei estadual é legítima caso esteja de acordo com a esfera de competência do Estado-membro para regular determinada matéria, nos termos da mesma Constituição Federal; de igual modo, uma lei municipal retira seu fundamento de validade do rol de competência que foi conferido ao município pela Constituição Federal.

Em síntese, a Constituição Federal é a lei fundamental e suprema do País, posteriormente vêm às normas primárias, seguido pelas normas regulamentadoras e normas coletivas e individuais. Cada norma jurídica tem sua finalidade em uma legislação, sempre com a função capital de determinar 
os direitos, deveres e obrigações de algo, servindo de parâmetros mínimos do que é necessário, como uma profissão ou atividade econômica. Por último, os Estados e Municípios também possuem legislações próprias em simetria com as de âmbito federal, mas não inferiores hierarquicamente, apenas diferenciadas pela sua esfera de competência.

\section{PROCEDIMENTO METODOLÓGICO}

Com uma abordagem qualitativa de natureza básica, esse estudo consiste em uma pesquisa exploratória pelo vasto mundo das leis brasileiras. Como procedimento metodológico foi realizado uma pesquisa bibliográfica e documental.

Na pesquisa bibliográfica, consistiu em uma busca exploratória sobre obras especificas que continham informações necessárias para pesquisa disponíveis pela internet, universidades, bibliotecas, entidades da classe, entre outros. Primeiramente, foi realizado um levantamento bibliográfico preliminar, com a finalidade de familiarização sobre o assunto abordado, criando as condições necessárias para iniciar o levantamento de dados. Pelo qual, consiste na identificação, localização e compilação das fontes escritas. Os dados obtidos, livros, teses, dissertações e artigos científicos, foram tratados preliminarmente, com leitura e fichamento, para contribuir na identificação e localização de fontes documentais da pesquisa documental.

A pesquisa documental propiciou a obtenção das leis do Brasil e de outros países referentes ao turismo e a profissão de guia de turismo, que contribui com o objetivo desse estudo. Primeiramente, identificando e localizando as fontes disponíveis em sites dos governos de diversos países (incluindo Brasil, Rússia, México e outros), de instituições, associações e sindicatos de turismo e dos guias de turismo (internacionais, nacionais e regionais). Posteriormente a obtenção desses materiais (leis, regulamentos, estatutos e outros) para serem tratados, com leitura e fichamento.

Os dados tratados das pesquisas bibliográficas e documental sofreram uma análise crítica, em uma busca por assimilação (familiaridade), maturação e clarividência das fontes obtidas. Resultando em construção lógica do texto 
ISSN: 1983-7151

que esclareça os direitos, os deveres e obrigações de um guia de turismo. Começando pelo Mundo e se concentrando no Brasil e seus Estados e Municípios, levantado uma relação histórica do turismo e da profissão de guia de turismo e comparando com as normas jurídicas atuais. Em uma busca de suas atribuições, do que é necessário para executar suas atividades e como ela é incluída dentro da indústria do turismo do Brasil.

\section{AS LEGISLAÇÕES SOBRE O GUIA DE TURISMO PELO MUNDO}

Segundo Valle (2004, p. 46), "não existe, ... uma regulamentação, internacionalmente aceita, para o guia de turismo. Cada país tem regulamentação própria e, até mesmo dentro de um país, essa regulamentação possui variações, dependendo nas necessidades locais". Na esfera mundial, o que existem são recomendações criadas pelos mais diversos órgãos e entidades mundiais, como a Organização Mundial do Turismo - World Tourism Organization (UNWTO).

Em 1999, essa organização, uma das agências especializadas da Organização das Nações Unidas (ONU), lançou o Código Mundial de Ética no Turismo com a função de promover a credibilidade ao setor e minimizar os impactos negativos providos do turismo em relação ao meio ambiente, patrimônio cultural e sociedade (UNWTO, 2016). Este código é formado por 10 artigos referentes aos destinos, governos, operadores turísticos, promotores, agentes de viagens, trabalhadores do turismo e turistas. Mesmo sendo considerado um marco histórico para indústria do turismo, ainda não trata sobre os guias de turismo diretamente, podendo ser incluído como trabalhadores do turismo.

A Federação Mundial de Associações de Guia de Turismo - World Federation of Tourist Guide Associations (WFTGA, 2016) e Federação Europeia de Associações de Guia de Turismo - European Federation of Tourist Guide Associations (FEG, 2016), associações internacionais que defendem os direitos dos guias de turismo, desenvolvem recomendações sobre o exercício das atividades desses profissionais. Dos quais, muitas são referentes à necessidade de um profissionalismo da categoria, por meio de cursos e capacitações e um reconhecimento dos governos e autoridades competentes. 
No Emirado de Dubai, pertencente aos Emirados Árabes Unidos, a Lei Municipal de Dubai (Bylaw of 2000 - Regulating the tour guide profession in the Emirate of Dubai), define o guia de turismo como uma pessoa que executa as atividades de orientação e acompanhamento de turistas para os vários locais turísticos no território. Também determina que o profissional tenha a necessidade de concluir um curso de formação profissional e a cada ano realizar um curso de reciclagem para sua renovação, como requisito para obter uma licença profissional. Além disso, dispõe que os comportamentos desses profissionais reflitam na imagem "civilizada" do Emirado, exigindo o cumprimento de um código de conduta, que caso do não cumprimento lhe acarretará a perda da licença e uma multa.

Na Republica de Singapura, a alteração da Lei de Turismo (Singapore Tourism Board (Amendment) Act 2014), define o guia de turismo como um indivíduo que pessoalmente fornece quaisquer serviços de orientação a um turista e é remunerado por isso. Ela exige uma licença emitida por um conselho dos profissionais para exercer a atividade, sem haver necessidade de um curso ou capacitação profissional.

Já dentro do território mexicano, a regulamentação da Lei Geral do Turismo de 2015 (Reglamento de la Ley General de Turismo), define esses profissionais como indivíduos que fornecem ao turista orientação e informação profissional sobre a localidade visitada. Para poderem exercer suas atividades no México, os guias de turismo devem ser aprovados por um processo de avaliação de conhecimento, habilidade e destreza para obter uma credencial da secretaria local de turismo.

\section{LEGISLAÇÃO SOBRE GUIA DE TURISMO NO BRASIL}

O turismo aparece na Constituição Federal de 1988 no Art. 180, que determina a responsabilidade da União, dos Estados, do Distrito Federal e dos municípios em promover e incentivar o turismo, com o objetivo de desenvolvimento econômico. Logo, todos os governantes (Federal, Estadual e Municipal) têm a responsabilidades com o turismo, tanto na promoção de 
políticas especificas como na regulamentação e fiscalização de profissionais ou atividades relacionadas, incluindo o desenvolvimento do mesmo.

Apesar de, não mencionar nada relacionado diretamente sobre o guia de turismo, esse artigo determina a responsabilidades dos governantes sobre o desenvolvimento de tudo que esteja relacionado ao turismo, inclusive dessa profissão. Segundo Badaró (2008), o Art. 180 torna o turismo num fator para o desenvolvimento social e econômico para o país, devido às responsabilidades dos legisladores constituintes têm de identificar os potencias e carências do turismo, que engloba o local como um todo.

Porém, assuntos relacionados ao turismo vêm sendo citados na legislação brasileira desde 1938, enquanto referências sobre o guia de turismo a partir de 1940, conforme mostra a Figura 01.

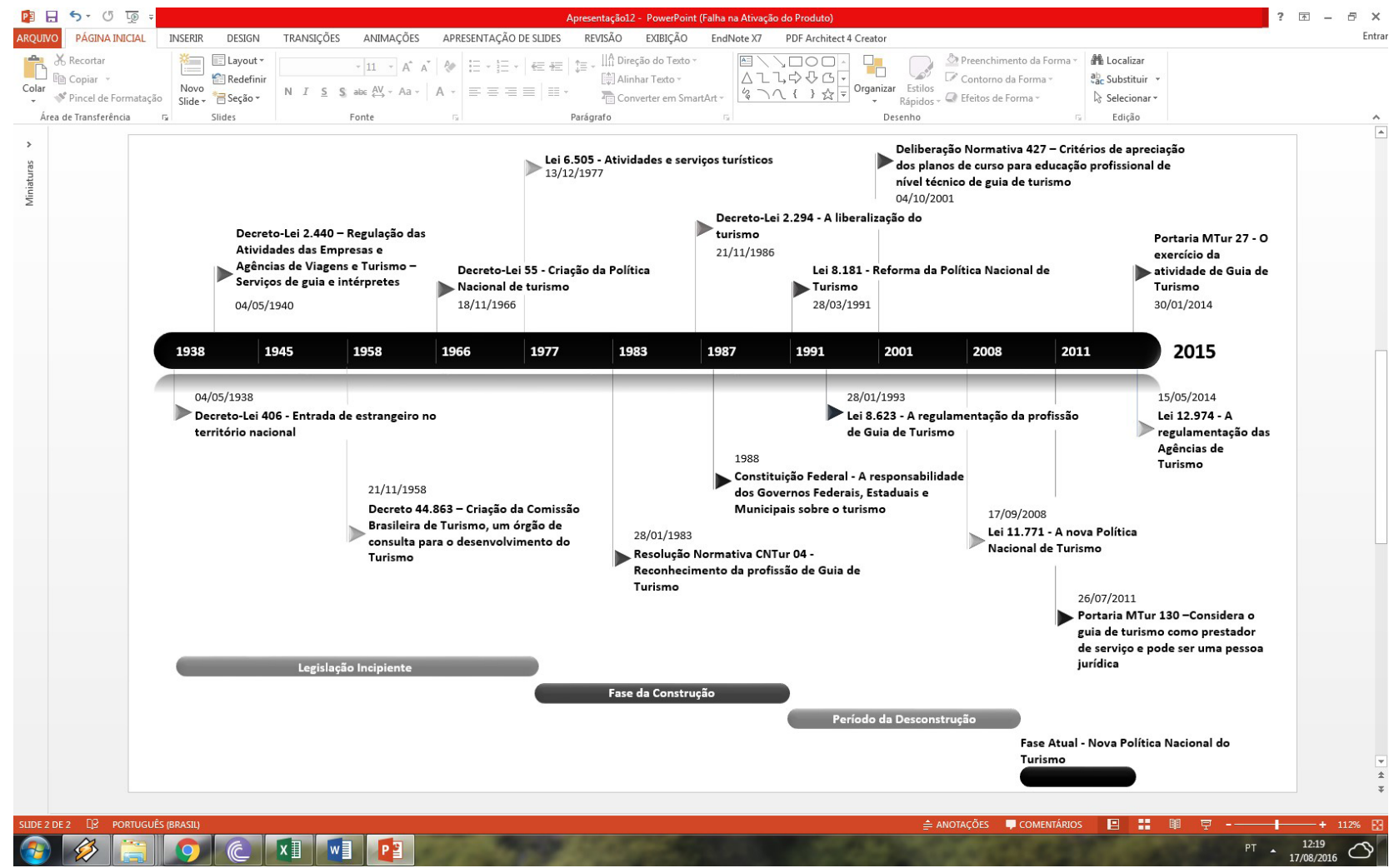

Figura 01. Linha do tempo referente à legislação do turismo. Elaborado pelos autores.

A Figura 01 consiste numa linha do tempo traçada sobre a evolução da legislação do turismo, incluindo o guia de turismo, ao longo dos anos. Para Badaró (2008), a evolução do turismo no Brasil está diretamente relacionada com as normas jurídicas criadas ao longo da história, sendo dividido (até 2008) em três períodos: legislação incipiente, fase da construção e período da desconstrução. 
Até 1966, segundo o mesmo autor, existiam as legislações incipientes consideradas o primeiro período da história das legislações sobre o turismo. Foi sucedida pela fase da construção, entre 1966 até 1986, devido à intervenção política e o controle das atividades econômicas pelo governo, por meio de criações de normas regulamentadoras. De 1986 até 2008 é marcado pelo fim da intervenção e arbítrio do governo, levando o turismo brasileiro a uma liberdade de ações econômicas, da concorrência, de ofício, entre outras, sendo denominado como o período da desconstrução. A Figura 01 traz referências desses três períodos que a legislação do turismo brasileira sofreu, com acréscimo do atual período, em que o turismo se restabelece pela nova Política Nacional do Turismo, estruturada em 2008.

Segundo o emérito advogado e professor Joandre Antônio Ferraz, citado Boiteux (2008), um dos primórdios da legislação turística no Brasil foi o DecretoLei $n^{\circ}$ 406, de 04 de maio de 1938, que se referiu à entrada de estrangeiros no país. Em seu Art. 12 fez referências sobre os estrangeiros de caráter temporário, podendo ser um turista ou um visitante em geral.

Dois anos depois, foi criado o Decreto-Lei n².440, de 23 de julho de 1940, que regula as atividades das empresas e agências de viagens e turismo. Mencionando na alínea e do inciso I, e também II, do Art. $1^{\circ}$, como responsabilidade das agências de viagens e turismo as atividades de Dinformação de qualquer gênero em matéria turística, inclusive serviços próprios de guias e intérpretes $\square$. Baseado nesse decreto-lei o guia de turismo é parte integrante dos serviços das agências de viagens e turismo.

Em 1958, o Governo Federal instituiu, por meio do Decreto $n^{\circ} 44.863$, de 21 de novembro, a Comissão Brasileira de Turismo (COMBRATUR), que era um órgão de consulta na coordenação de atividades destinadas ao desenvolvimento do Turismo no País. Esses decretos foram o primeiro passo a organização e o desenvolvimento do turismo no Brasil.

Para Boiteux (2008), o principal antecedente jurídico do turismo foi criado em 1966, com a aprovação do Decreto-Lei n 55, de 18 de novembro. A partir desse momento inicia-se a fase de construção das legislações do turismo. O decretolei implantou a Política Nacional de Turismo, com a obrigação de desenvolver o 
turismo. Criando a EMBRATUR, que naquela época foi determinada com o nome Empresa Brasileira do Turismo, e o Conselho Nacional de Turismo (CNTur).

Onze anos depois, vigorou à primeira legislação referente aos profissionais do turismo. A Lei n 6.505, de 13 de dezembro de 1977, dispõe sobre as atividades e serviços turísticos, reconhecendo empresas e prestadores dos serviços turísticos registradas na EMBRATUR. Em nenhum momento desta lei o guia de turismo foi mencionado ou considerado como um prestador de serviços turísticos.

Porém, no ano de 1983, a Resolução Normativa CNTur nº 04 de 28 de janeiro, foi à primeira ação referente à profissão de guia de turismo, dos quais as agências de turismo eram recomendadas a ter em um representante durante as excursões ou serviços receptivos que operem. Nessa resolução o indivíduo que executa as atividades de guiamento deveria ser cadastrado na EMBRATUR ou por um órgão delegado competente, podendo ser classificado, segundo o Art. 11, da seguinte forma:

- Guia Local - desempenha as atividades de acompanhar e informar os turistas apenas em uma localidade determinada e suas vizinhanças;

- Guia de Excursão - desempenha as atividades de acompanhar, informar e prestar assistência permanente aos turistas em toda a viagem;

- Guia Especializado - desempenha as atividades de acompanhar e informar questões técnicas especifica sobre um determinado tipo de empreendimento ou atrativo turístico.

Em 1986, teve o início o período da desconstrução com a liberalização do turismo no Brasil. O Decreto-Lei n².294, de 21 de novembro, permitiu que o registro por parte dos prestadores de serviços não era mais obrigatório. $O$ governo apenas manteria a fiscalização e classificação dos mesmos, acreditando que essa ação melhoraria a qualidade do produto turístico. Em contrapartida, criou um caos turístico, com a perda do controle sobre esses profissionais (BOITEUX, 2008).

No início da década de 90, a Empresa Brasileira de Turismo torna-se o Instituto Brasileiro de Turismo, mantendo a sigla EMBRATUR, e CNTur foi extinta, 
junto com a Resolução Normativa CNTur n 04 de 28 de janeiro de 1983, que reconhecia o guia de turismo. A Lei no 8.181 de 28 de março de 1991, teve a função de alterar a Política Nacional de Turismo, transformando uma empresa pública em um instituto, sendo o principal instrumento no desenvolvimento do turismo brasileiro.

Dez anos depois do reconhecimento dos guias de turismo no Brasil, aconteceu à regulamentação da profissão. A Lei no 8.623, de 28 de janeiro de 1993, em seu Art. $2^{\circ}$, considera o guia de turismo "o profissional que, devidamente cadastrado no Instituto Brasileiro de Turismo (EMBRATUR), exerça atividades de acompanhar, orientar e transmitir informações a pessoas ou grupos, em visitas, excursões urbanas, municipais, estaduais, interestaduais, internacionais ou especializadas". No Art. 9, determina que o guia de turismo deva exercer sua atividade com "dedicação, decoro e responsabilidade, zelando pelo bom nome do turismo no Brasil e da empresa à qual presta serviços". Caracterizando que no Brasil, uma guia de turismo tem um papel de acompanhar, orientar e informar com dedicação, decoro e responsabilidade, criando uma boa relação entre o turista, o País e a empresa que representa.

Por sua vez, o Decreto n 946, de 01 de outubro de 1993, além de regulamentar a Lei $n^{\circ} 8.623$, de 28 de janeiro de 1993, determina todo processo de como um indivíduo pode ser tornar um guia de turismo no País. Pelo qual, exige a conclusão de um curso de formação profissional especifico para cada classificação em uma instituição aprovadas pela EMBRATUR ou tenha-se formado em um curso superior de turismo e cursado cadeira especializada na formação de guia de turismo.

Nesse decreto, também trata sobre as infrações e penalidades que o profissional poderá sofrer, com o não cumprimento da lei e do próprio decreto. Já o Art. $4^{\circ}$ define as classificações dos tipos de guias de turismo, dos quais podem ser:

- Regional - atividades realizadas em roteiros locais ou intermunicipais de uma determinada unidade de federação;

- Nacional - atividades realizadas em roteiros em todo o território brasileiro ou na América do Sul; 
- Internacional - atividades realizadas em roteiros para os demais países; e

- Especializado em atrativos turísticos - atividades que compreenderem a prestação de informações técnico-especializadas sobre determinado tipo de atrativo natural ou cultural.

No entanto, somente em 2001 a EMBRATUR, por meio da Deliberação Normativa $n^{\circ} 427$ de 04 de outubro, mencionou os critérios de apreciação dos planos de curso para educação profissional de nível técnico de guia de turismo, complementado os dizeres do Decreto n 946, de 01 de outubro de 1993.

A reformulação ou renovação da Política Nacional de Turismo, em 2008, determinou o começo de uma nova fase para o turismo. Em que, a Lei $n^{\circ} 11.771$, de 17 de setembro, denominada como a "Lei Geral do Turismo", estabelece normas sobre a Política Nacional do Turismo, definindo a função do governo no planejamento, desenvolvimento e estimulo para indústria do turismo. Dando poderes ao Ministério do Turismo de estabelecer a Política Nacional do Turismo e de planejar, fomentar, regulamentar, coordenar, promover e fiscalizar a atividade turística. Já no seu Art. $2^{\circ}$ define que:

Para os fins desta Lei, considera-se turismo as atividades realizadas por pessoas físicas durante viagens e estadas em lugares diferentes do seu entorno habitual, por um período inferior a 1 (um) ano, com finalidade de lazer, negócios ou outras.

Define como os prestadores de serviços turísticos, conforme Art. 21, "as sociedades empresariais, sociedades simples, os empresários individuais e os serviços sociais autônomos que prestaem serviços turísticos remunerados e que exerçam atividades econômicas relacionadas à cadeia produtiva do turismo". Incluindo os meios de hospedagem, agências de turismo, transportadoras turísticas, organizadoras de eventos, parques temáticos e acampamentos turísticos. No entanto, em nenhum momento dessa lei é mencionado o guia de turismo. Logo, esse profissional não era considerado como prestador de serviços, mas sim um serviço oferecido pelas agências de turismo.

A partir de 2011, devido aprovação da Portaria MTur n 130, de 26 de julho, o guia de turismo pode se cadastrar como uma atividade econômica, por meio do 
microempreendedor individual (MEI). O MEI foi instituído pelo Governo Federal em 2008 pela Lei complementar $n^{\circ} 128$, de 19 de dezembro, com a finalidade eliminar o trabalho informal existente no Brasil, transformando uma pessoa que trabalha por conta própria em pequeno empresário, uma pessoa jurídica. Nesse momento, o guia de turismo pode ser uma pessoa física e também uma pessoa jurídica.

Porém, essa mesma portaria também institui o Cadastro dos Prestadores de Serviços (CADASTUR) e Comitê Consultivo do CADASTUR, devido à necessidade de ordenar a prestação de serviços turísticos. Considerando como prestadores de serviços turísticos, conforme o Art. $2^{\circ}$, sociedades empresariais de qualquer natureza, sociedades simples, empresas individuais, profissionais autônomos, os serviços sociais autônomos, bem como cada uma de suas projeções em qualquer parte do País. Pelo qual, o guia de turismo é mencionado como um desses prestadores.

Em 2014, o MTur estabeleceu normas que disciplinam o exercício da atividade de Guia de Turismo requisitos e critérios para o exercício das atividades de guia de turismo, por meio da Portaria MTur n²7, de 30 de janeiro. Disponibilizado de forma organizada, parecido com um código, em capítulos sobre as disposições gerais, deveres, exercício regular da atividade, cadastro, fiscalização, penalidades e disposições finais.

Dentro do capítulo "das disposições gerais", tanto no Art. $6^{\circ}$ quanto no $7^{\circ}$ condicionam o guia de turismo excursão (nacional ou regional) a representar a agência de turismo quando necessário, inclusive na contratação de outros profissionais. Como também o assessoramento técnico e a assistência necessária aos turistas.

Já o capítulo "do exercício regular da atividade", primeiramente trata da exigência do guia de turismo de apresentar um certificado ou diploma de conclusão de curso específico de educação profissional de nível técnico e do cadastro junto ao Ministério do Turismo na categoria para a qual estiver habilitado, conforme determinam os Art. 10 e 11. Posteriormente, só poderá exercer sua atividade, segundo o Art. 12, "por meio de contrato de prestação de serviço na qualidade de funcionário de agência de turismo ou transportadora 
turística cadastradas junto ao Ministério do Turismo, ou firmado diretamente com o consumidor final".

Por fim, com o objetivo de eliminar as informalidades nas atividades do turismo, a Lei n ${ }^{\circ} 12.974$, de 15 de maio de 2014, determina que uma pessoa física não possa organizar passeios, viagens ou excursões. Essa lei tem a finalidade de regulamentar as atividades das agências de turismo, porém a ocupação de agente de turismo não é regulamentada.

Nas legislações em âmbito nacional o turismo existe desde 1938, início do período das legislações incipiente. Nesse período as atividades de guia de turismo aparecem como parte integrante das agências de turismo. A partir de 1966 até 1986 veio o período da construção, pelo qual em 1983 o guia de turismo foi mencionado pela primeira vez como ocupação e não mais como apenas uma atividade. Posteriormente, veio o período da desconstrução (19862008) e com ele a regulamentação do guia de turismo e a responsabilidade dos governantes (federal, estadual e municipal) de desenvolvê-los. Porém, na fase atual (a partir de 2008), a nova Política Nacional do Turismo desconsidera essa profissão como prestador de serviços turísticos ao não mencionar na Lei Geral do Turismo. O guia de turismo como prestador de serviços veio se confirmar em 2011 pelo MTur, que também passam a aceitar como uma pessoa jurídica, além, claro, como uma pessoa física. Por fim, no ano de 2014, foram estabelecidas normas que disciplinam o exercício da atividade de guia de turismo no território brasileiro, algo parecido com um "código do guia de turismo".

\section{LEGISLAÇÕES ESTADUAIS E MUNICIPAIS SOBRE O GUIA DE TURISMO}

A maioria das legislações estaduais e municipais tem a função de regulamentar o exercício da profissão do guia de turismo, complementado as normas jurídicas federais. Esse ato é justificado pelo Art. 180 da Constituição Federal que dá responsabilidades aos Estados, municípios e o Distrito Federal.

Em Alagoas, por exemplo, a Lei estadual n 6.943, de 12 de junho de 2008, regulamenta o exercício da profissão do guia de turismo no Estado. Define no parágrafo único do Art. $1^{\circ}$ a atividade do guia de turismo regional, que "compreende a recepção, o translado, o acompanhamento, a prestação de 
informações e assistência em geral a turistas em itinerários ou roteiros, locais ou intermunicipais, de uma determinada Unidade da Federação".

No município de Florianópolis é disponibilizado de um ato jurídico que trata sobre as atividades turísticas nessa cidade. A Lei municipal n 5.240, de 08 de janeiro de 1998, tem foco sobre os guias de turismo regionais. Tratando sobre a obrigatoriedade de todos os grupos ou excursões serem acompanhados com esse profissional. Também, propõe a promover exames periódicos de avaliação e cursos de atualização sobre o município.

No Art. $6^{\circ}$ determina que "No exercício da função, o Guia de Turismo deverá conduzir-se com probidade, dedicação e responsabilidade zelando sempre pelo bom nome da SETUR (Secretária Municipal de Turismo), devendo ainda, respeitar e cumprir as Leis e regulamentos que disciplinam sua atividade". Nesse artigo, o guia de turismo tem a responsabilidade de zelar pelo nome da SETUR e não do município de Florianópolis.

\section{GUIA DE TURISMO COMO ATIVIDADE ECONÔMICA E OCUPAÇÃO}

Atualmente, o Governo Federal classifica o guia de turismo com uma atividade econômica e ocupação conforme o Conselho Nacional de Atividades Econômicas (CNAE) e Código Brasileiro de Ocupação (CBO).

Segundo o Ministério da Fazenda (2016), o CNAE é uma classificação usada com o objetivo de padronizar a identificação das unidades produtivas, informando a natureza, a definição e particulares de cada atividade. No entanto, o turismo não aparece como apenas uma única atividade econômica, mas está conectada em cada um dos prestadores de serviços, principalmente a atividade de agência de turismo e transportadora turística. As atividades do guia de turismo pertencem à seção $N$ (atividades administrativas e serviços complementares), divisão 79 (agências de viagens, operadores turísticos e serviços de reservas), grupo 791 (agências de viagens e operadores turísticos), classe 7912-1 (operadores turísticos), subclasse 7912-1/00 (operadores turísticos), como é mostrado na Quadro 01. 


\begin{tabular}{|c|c|c|}
\hline Classificação & Código & Descrição \\
\hline CNAE 2.2 & $\begin{array}{c}\text { 7912-1/00 - Serviços de Guia de } \\
\text { Turismo }\end{array}$ & $\begin{array}{l}\text { Determina que esta subclasse compreenda as } \\
\text { atividades do guia turismo, mas não a descreve. }\end{array}$ \\
\hline CBO (2010) & $\begin{array}{l}\text { 5114-05 - Guia de turismo } \\
\text { especializado em atrativo } \\
\text { turístico, excursão nacional ou } \\
\text { internacional, e turismo regional. }\end{array}$ & $\begin{array}{l}\text { Executam roteiros turísticos, transmitem } \\
\text { informações, atendem passageiros, organizam as } \\
\text { atividades do dia, realizam tarefas burocráticas e } \\
\text { desenvolvem itinerários e roteiros de visitas. }\end{array}$ \\
\hline
\end{tabular}

Quadro 01. Classificação da atividade e ocupação de guia de turismo no Brasil. CNAE 2.2 (2016) e CBO (2010).

Já o CBO, segundo o Ministério do Trabalho e Emprego (MTE, 2010), tem o objetivo de padronizar as ocupações no território brasileiro. Várias atividades relacionadas ao turismo são referenciadas nesse código. Por sua vez, os guias de turismo pertencem ao grande grupo 5 (trabalhadores dos serviços, vendedores do comércio em lojas e mercados), subgrupo principal 1 (trabalhadores dos serviços), subgrupo 1 (trabalhadores dos serviços de transporte e turismo), grupo de base ou familiares 4 (ocupação de guia de turismo), conforme descrito no Quadro 01.

Essas duas classificações determinada pelo Governo Federal, por meio de seus ministérios, considera o guia de turismo ao mesmo tempo uma atividade econômica e uma ocupação. Por ser uma atividade econômica é permitido ser uma pessoa jurídica, uma empresa, que oferece os seus serviços a que tem o interesse. Como ocupação depende de sua escolha a relação de trabalho que pretende praticar com seu contratante.

\section{RELAÇÃO DE TRABALHO DO GUIA DE TURISMO NO BRASIL}

Em primeiro lugar, certos cuidados devem ser esclarecidos sobre a relação de trabalho do guia de turismo, por ser regulamentada o mesmo se enquadra como um profissional liberal. Segundo a Confederação Nacional das Profissões Liberais (CNPL, 2015) é a pessoa com nível superior ou técnico, habilitado legalmente, com autonomia técnico-cientifica de cunho profissional, independentemente da relação de trabalho.

Em outras palavras, o guia de turismo tem liberdade de como executar suas atividades sem qualquer tipo de interferência, como também de definir a forma 
de prestação de serviço a ser executada. Na opinião de Merçon (2005), a relação de trabalho refere-se ao gênero das diversas formas de prestação de serviço, podendo ser eventual, continuo, temporário, avulso, contratual ou informal. De acordo com Saraiva (2006, p. 34), "relação de trabalho corresponde a qualquer vínculo jurídico por meio do qual uma pessoa natural executa obras ou serviços para outrem, mediante o pagamento de uma contraprestação".

Porém, a legislação brasileira apresenta dois tipos de relação de trabalho: relação de emprego (vínculo empregatício), relação de trabalho (prestador de serviços habitualmente ou eventual e por execução de obras). Aqueles que não possuem nenhuma dessas relações praticam o trabalho informal, em que prevalece o mínimo de intervenção do governo (Chahad, 1996) e sem todos os benefícios legais de um trabalhador formalizado (Oliveira \& Piccinini, 2011).

A relação de emprego engloba todos os trabalhadores contratados seguindo a Consolidação das Leis Trabalhista (CLT), do Decreto-Lei $n^{\circ}$ 5.452, de 01 de maio de 1943. A CLT, segundo Granconato (2013), é o instrumento que rege as relações de emprego (relações individuais ou coletivas), definindo direitos, deveres e obrigações entre empregado e empregador. Cujo grande parte dos direitos dos trabalhadores são regidos por este código (Martins, 2010).

Enquanto, a relação de trabalho, inclui a maioria dos outros tipos de trabalhadores com contratos de trabalho baseado no capítulo VII (prestação de serviços), VIII (empreiteiros) ou XI (representantes comerciais) do Código Civil (CC), da Lei no 10.406, de 10 de janeiro de 2002. O CC, segundo Rodrigues (2013), é um conjunto de normas referentes às relações jurídicas de ordem privada. Por sua vez, o capítulo VIII trata sobre a prestação de serviços de cunho exclusivamente civil, em que não há relação de emprego, somente de trabalho, do qual o guia de turismo pode estar incluído.

Nessa modalidade de vinculo o guia de turismo se torna um trabalhador autônomo, previsto na legislação previdenciária alínea h do inciso V do Art. 12 da Lei n 8.212 de 24 de julho de 1991, como "a pessoa física que exerce, por conta própria, atividade econômica de natureza urbana, com fins lucrativos ou não". Mas, para Silva e Rezende (2016, p. 40), "é a pessoa física que exerce, habitualmente e por conta própria, atividades profissional remunerada, 
prestando serviços de caráter eventual a uma ou mais empresas, sem relação de emprego". Pelo qual, não é subordinado e assume os riscos da própria prestação laborativa.

Além de, poder ter uma relação de emprego ou de trabalho com seu contratante, o guia de turismo por ser uma atividade econômica, pode ser uma pessoa jurídica e constituir uma empresa, que ofereça serviços de guiamento. Dos quais, pode-se citar: o MEI, previstos pela Portaria MTur no 130, de 26 de julho de 2011 e Lei complementar no 128, de 19 de dezembro de 2008; e o cooperador, trabalhador associado à cooperativa previsto pelo CC, uma associação de pessoas com interesses comuns, economicamente organizada de forma democrática (Julião at al., 2009 e Silva e Rezende, 2016).

O Quadro 02 faz uma síntese de como o guia de turismo pode apresentar profissionalmente, como profissional liberal (relação de emprego, trabalho ou informal) ou atividade econômica (cooperador, MEI ou outros tipos de pessoas jurídicas).

\begin{tabular}{|c|c|c|}
\hline \multicolumn{2}{|c|}{ O Guia de Turismo Como: } & Descrição \\
\hline \multirow{3}{*}{$\begin{array}{l}\text { Profissional } \\
\text { Liberal }\end{array}$} & Relação de Emprego & $\begin{array}{l}\text { Trabalho não eventual com garantias dos direitos trabalhistas } \\
\text { previsto pela Constituição Federal de } 1988 \text { e pela CLT. }\end{array}$ \\
\hline & Relação de Trabalho & $\begin{array}{l}\text { Trabalho habitual ou eventual, com os direitos definidos em } \\
\text { contrato de prestação de serviços regido pelo CC. }\end{array}$ \\
\hline & Trabalhador Informal & $\begin{array}{l}\text { Trabalho que não possui nenhuma formalidade e garantias de } \\
\text { direitos. }\end{array}$ \\
\hline \multirow{3}{*}{$\begin{array}{l}\text { Atividade } \\
\text { Econômica }\end{array}$} & Cooperativa & $\begin{array}{c}\text { Junção de um grupo de profissionais, com função de um ajudar } \\
\text { o outro para que ambos possam ter sucessos profissionais. }\end{array}$ \\
\hline & MEI & Torna-se um pequeno empresário de serviço de guiamento. \\
\hline & $\begin{array}{l}\text { Outros tipos de } \\
\text { pessoas jurídicas }\end{array}$ & $\begin{array}{l}\text { Torna-se um empresário de terceirização do serviço de } \\
\text { guiamento. }\end{array}$ \\
\hline
\end{tabular}

Quadro 02 - Relação de trabalho. Fonte: Elaborados pelos autores.

Cabe lembrar que, segundo o Art. 12 da Portaria MTur n²7, de 30 de janeiro de 2014, o guia de turismo deve ser uma pessoa física que presta serviço eventual ou não, formalizado em um contrato de trabalho. Logo, não poderia ser uma pessoa jurídica. 
Outro ponto conflitante existente está na possibilidade de o guia de turismo constituir um MEI, com a função de inibir o trabalho informal. O guia de turismo é um profissional liberal, como tal não necessita constituir um MEI para exercer sua atividade, pois é um prestador de serviços profissional, em que seu status permite atuar como empreendedor e empregador, semelhante a uma pessoa jurídica, conforme determina a Instrução Normativa da Receita Federal do Brasil No 971, de 13 de novembro de 2009. Na opinião de Zugman (2012), os prestadores de serviços profissionais (profissionais liberais), como médicos, advogados, contadores, arquitetos, psicólogos e outros profissionais são denominados como empreendedores esquecidos, devido à falta de uma compreensão da sociedade sobre eles.

No entanto, nenhuma outra forma de pessoa jurídica da atividade econômica do guia de turismo é equivalente ou semelhante à execução das atividades do profissional liberal. Primeiramente, conforme CNLP (2015), profissional liberal é uma pessoa e não uma empresa e, segundo o Art. 12 da Portaria MTur n²7, de 30 de janeiro de 2014, o guia de turismo é uma pessoa física e não jurídica.

Por outro lado, em uma cooperativa de guias de turismo, os profissionais se unem para que todos tenham oportunidade de trabalho de uma forma organizada. Enquanto, em outros tipos de pessoas jurídicas é uma empresa prestadora de serviços de guiamento, podendo ser uma agência de turismo, no qual o profissional liberal na qualidade de empregado ou terceirizado presta seus serviços a outras empresas ou diretamente para os turistas.

Enfim, a legislação brasileira permite interpretar que os guias de turismo têm o direito de escolher a forma de exercer suas atividades, ou como uma pessoa física ou pessoa jurídica. Por ser uma profissional liberal tem a liberdade de definir a sua relação de trabalho, enquanto como atividade econômica encontra-se numa situação duvidosa sobre a necessidade de se tornar uma, principalmente como MEI.

\section{SINDICATO E O GUIA DE TURISMO}

Silva e Rezende (2016, p. 18) definiram que o sindicato "consiste em uma associação coletiva, de natureza privada, voltada a defesa e incremento de interesses coletivos profissionais e materiais de trabalhadores, sejam 
subordinados ou autônomos, e de empregadores". Regulada no Art. $8^{\circ}$ da Constituição Federal de 1988, pelo qual "ao sindicato cabe a defesa dos direitos e interesses coletivos ou individuais da categoria, inclusive em questões judiciais ou administrativas" (inciso III); e Título V da CLT, em que o Art. 511 define que:

É lícita a associação para fins de estudo, defesa e coordenação dos seus interesses econômicos ou profissionais de todos os que, como empregadores, empregados, agentes ou trabalhadores autônomos ou profissionais liberais exerçam, respectivamente, a mesma atividade ou profissão ou atividades ou profissões similares ou conexas.

Tanto o Art. $8^{\circ}$ da Constituição Federal de 1988 quanto Art. 511 da CLT dão o direito dos guias de turismo a organizar, de aderir (a um de sua escolha) ou não se filiar a um sindicato, para que possam buscar os seus interesses coletivos profissionais. Logo, o guia de turismo não é obrigado a pertencer nenhum sindicato, mas pode filiar-se no de seu interesse, como um que englobe a sua categoria ou até um relacionado aos profissionais do turismo.

No Brasil, existem os sindicatos dos guias de turismo, como as SINDEGTUR e SINGTUR (Sindicato dos Guias de Turismo) de cada Estado ou Região do Brasil; e os sindicatos dos trabalhadores em turismo e hospitalidade, as SINTRATUH (Sindicato dos Trabalhadores em Turismo e Hospitalidade) e SINTUR (Sindicato dos Trabalhadores e Profissionais do Turismo) existente em diversas regiões e municípios do território brasileiro. Alguns desses sindicatos definiram um referencial de remuneração a ser aplicada por esses profissionais, no entanto não é uma determinação obrigatória para ser seguida, e sim apenas uma recomendação, conforme citado pelo Sindicato Estadual dos Guias de Turismo do Estado do Rio de Janeiro (SINDEGTUR/RJ, 2016). Outros, como o Sindicato dos Guias de Turismo de Foz do Iguaçu e Região (SINGTUR/FOZ, 2016) e Sindicato dos Trabalhadores em Hotéis, Restaurantes, Bares, Lanchonetes e de do Turismo e Hospitalidade da Grande Florianópolis (SITRATUH/Florianópolis, 2016), consolidaram uma Convenção Coletiva de Trabalho (CCT), definindo piso salarial e outros direitos trabalhistas para esse profissional em uma relação de emprego com as agências de turismo ou outras empresas.

\section{CONCLUSÃO}

O guia de turismo é uma profissão reconhecida pelo mundo e regulamenta em diversos países, incluindo o Brasil. Um País filiado a Organização Mundial de 
Turismo (UNWTO, 2016), pelo qual, em muitos casos, adota as recomendações providas das convenções (normas supralegais) estabelecidas dentro de sua legislação. Muitas de suas recomendações são adotas nas regulações do guia de turismo, principalmente a necessidade da realização de um curso de formação especifica e de serem registrado por um órgão competente.

Cabe aos governos tanto de âmbito federal quanto de estadual e municipal, determinado por uma norma suprema e fundamental - Constituição Federal de 1988, a responsabilidade no desenvolvimento das atividades relacionada com o turismo, inclusive as de guias de turismo.

Por sua vez, essa profissão é regulamentada, por uma norma ordinária, uma lei ordinária, a Lei n 8.623 , de 28 de janeiro de 1993. Essa lei é regulamentada e complementada por três normas regulamentadoras, um decreto regulamentar, o Decreto n 946, de 01 de outubro de 1993 e duas portarias, a Portaria MTur n. 130, de julho de 2011 e a Portaria MTur no. 27, de 30 de janeiro de 2014. Em muitos Estados e Municípios as atividades dos Guias de Turismo são regulamentadas por meio de norma ordinárias do tipo lei ordinárias, como no Estado de Alagoas, a Lei no. 6.943, de 12 de junho de 2008; e no Município de Florianópolis/SC, a Lei n. 5.240, de 08 de janeiro de 1998.

Por um lado, o guia de turismo pode ser uma pessoa física, profissional liberal (baseado no estatuto da CNPL (2015), uma norma infralegal coletiva), equiparado a uma empresa (conforme Instrução Normativa da Receita Federal do Brasil No 971, de 13 de novembro de 2009, uma norma infralegal coletiva), empregado (segundo CLT, uma norma ordinária do tipo código), trabalhador autônomo (em relação CC, uma norma ordinária do tipo código) ou trabalhador informal. Com direitos trabalhistas ou assumindo os próprios riscos, sendo subordinado ou definindo como trabalhar. Por outro lado, pode ser uma pessoa jurídica, empresa (baseado no CC), MEI (conforme Lei complementar $n^{\circ} 128$, de 19 de dezembro de 2008, uma norma fundamental do tipo lei complementar e segundo a Portaria MTur $n^{\circ}$ 130, de 26 de julho de 2011) ou cooperador (segundo (C), mas não um profissional liberal.

Em se tratando de direitos trabalhista, alguns guias de turismo, somente os que possuem uma relação de emprego, são beneficiados pelas CCT's, normas 
infralegais coletivas, estabelecida entre os sindicatos patronais do turismo e os dos profissionais do turismo (incluído o guia do turismo), como os Foz do Iguaçu/ PR e Região (SINGTUR/FOZ, 2016) e o da Grande Florianópolis (SITRATUH/ Florianópolis, 2016). Para aqueles que não possuem uma relação de trabalho, os sindicatos da categoria fixam valores da remuneração a ser aplicada por seus afiliados em seus contratantes, como recomendação.

No entanto, por mais que a legislação brasileira possa ser complexa e emaranhada, conforme citou Valle (2004), elas referenciam o guia de turismo. Sua complexidade não está inerente nas contradições e sobreposições, mas na interpretação do seu ordenado jurídico. A Constituição, uma norma suprema e fundamental, prevalece sobre as normas fundamentais e ordinárias, que por sua vez elas sobre as regulamentares e infralegais, não importando se é de âmbito federal, estadual ou municipal (Paulo \& Alexandrino, 2008, Ferraz Junior, 2015).

Já a inexistência da garantia dos direitos trabalhista, conforme afirmou Julião at al. (2009), não está totalmente fadada à imposição do mercado, mas também pelos interesses dessas profissionais. Por serem profissionais liberais podem adotar a relação de trabalho do seu interesse (CNPL, 2015). Como empregado seus direitos corresponde pela CLT, enquanto como prestadores de serviços definem seus direitos imersos em um contrato de trabalho (norma infralegal individual) baseado no CC, mas como informal eles abdicam dos seus direitos trabalhistas. Contudo, não se pode afirmar que o guia de turismo não tenha direitos trabalhista, eles possuem, mas talvez os desconheçam ou não se disponibilizam de uma assistência ou orientação jurídica sobre o caso.

Portanto, a situação do guia de turismo no Brasil, que é reconhecido e regulamentado na legislação, tem direitos, deveres e obrigações a exigir e cumprir. Dos quais, tem a liberdade de escolha sobre a sua relação de trabalho, influenciando nas questões referentes sobre seus direitos trabalhistas.

Ainda que, o guia de turismo seja uma profissão importante para o turismo, necessita ser explorado com base em múltiplas abordagens possíveis. Esta pesquisa quis proporcionar, por meio das legislações existentes e de suas antecessoras, uma contribuição para estudos futuros sobre esse fenômeno, possibilitando o seu desenvolvimento e sua evolução. 
Badaró, R. A. L. (2008). Turismo (constitucional?!?). In: Badaró, R. A. L. (org.). Estudos de direito do turismo: perspectivas de direito comparado europeu e latino-americano. São Paulo: IBCDTur.

Boiteux, B. C. (2008). Legislação de turismo: tópicos de direito aplicados ao turismo (3a ed.). Rio de Janeiro: Elsevier.

Bylaw of August 10, 2000. (2000). Regulating the Tour Guide Profession in the Emirate of Dubai, Dubai, Emirados de Dubai, Emirados Árabes Unidos. Recuperado em 01 mar. 2016, de https://www.visitdubai.com/ /media/pdfs/legislation/tour\%20guides/2\%20-\%20 bylaw\%20regulaing\%20tour\%20guide\%20profession_final\%20110315\%20-\%20en.ashx

Chahad, J. P. Z. (1996). Mercado de trabalho: conceitos, definições e funcionamento. In: Pinho, D. B., \& Vasconcellos, M. A. S. (coord.). Manual de economia (2a ed.). São Paulo: Saraiva.

CNAE. (2016). O que é? Recuperado em 01 mar. 2016, de http://subcomissaocnae.fazenda. pr.gov.br/modules/conteudo/conteudo.php?conteudo $=1$

CNPL. (2015). Estatuto Social da Confederação Nacional das Profissões Liberais. Brasília, DF, Brasil.

Constituição da República Federativa do Brasil de 1988. (1988). Brasília, DF, Brasil. Recuperado em 01 mar. 2016, de http://www.planalto.gov.br/ccivil_03/constituicao/ ConstituicaoCompilado.htm

Cunha, M. I. M. S. A. (2010). Direito do Trabalho (6a ed. rev. e atual.). São Paulo: Saraiva.

Decreto $\mathrm{n}^{\circ}$ 44.863, de 21 de novembro de 1947. (1947). Institui a Comissão Brasileira de Turismo. (COMBRATUR). Brasília, DF, Brasil. Recuperado em 01 mar. 2016, de http://www2. camara.leg.br/legin/fed/decret/1950-1959/decreto-44863-21-novembro-1958-383896publicacaooriginal-1-pe.html

Decreto no 946, de 01 de outubro de 1993. (1993). Regulamenta a Lei $n^{\circ}$ 8.623, de 28 de janeiro de 1993, que dispõe sobre a profissão de Guia de Turismo e dá outras providências. Brasília, DF, Brasil. Recuperado em 01 mar. 2016, de http://www.planalto.gov.br/ccivil_03/ decreto/Antigos/D0946.htm

Decreto-Lei $n^{\circ}$ 406, de 04 de maio de 1938. (1938). Dispõe sobre a entrada, de estrangeiros no território nacional. Brasília, DF, Brasil. Recuperado em 01mar. 2016, de http://legis.senado. gov.br/legislacao/ListaPublicacoes.action?id=12803 
Decreto-Lei $n^{\circ} 2.440$, de julho de 1940. (1940). Regula as atividades das empresas e agências de viagens e turismo. Brasília, DF, Brasil. Recuperado em 01 mar. 2016, de http://www2. camara.leg.br/legin/fed/declei/1940-1949/decreto-lei-2440-23-julho-1940-412448publicacaooriginal-1-pe.html

Decreto-Lei n 5.452, de 01 de maio de 1943. (1943). Aprova a Consolidação das Leis do Trabalho. Brasília, DF, Brasil. Recuperado em 01 mar. 2016, de http://www.planalto.gov.br/ ccivil_03/decreto-lei/del5452.htm

Decreto-Lei $\mathrm{n}^{\circ}$ 55, de 18 de novembro de 1966. (1966). Define a política nacional de turismo, cria o Conselho Nacional de Turismo e a Empresa Brasileira de Turismo, e dá outras providências. Brasília, DF, Brasil. Recuperado 01 mar. 2016, de http://www.planalto.gov.br/ ccivil_03/decreto-lei/1965-1988/Del0055.htm

Decreto-Lei $n^{\circ} 2.294$, de 21 de novembro de 1986. (1986). Dispõe sobre o exercício e a exploração de atividades e serviços turísticos e dá outras providências. Brasília, DF, Brasil. Recuperado em 01 mar. 2016, de http://www.planalto.gov.br/ccivil_03/decreto-lei/19651988/Del2294.htm

Deliberação Normativa da EMBRATUR no 427, de 04 de outubro de 2001. (2001). Brasília, DF, Brasil. Recuperado em 10 jun. 2016, de http://www.portaleducacao.com.br/turismo-ehotelaria/artigos/4291/deliberacao-normativa-n-427-de-04-de-outubro-de-2001

Diniz, M. H. (2012). Curso de direito civil brasileiro, volume 1: teoria geral do direito civil (29a ed). São Paulo: Saraiva.

FEG. (2016). European Federation of Tourist Guide Associations. Recuperado em 01 mar. 2016, de http://www.feg-touristguides.com

Ferraz Junior, T. S. (2015). Introdução ao estudo do direito: técnica, decisão, dominação (8a ed.). São Paulo: ATLAS.

Granconato, M. M. (2013). Arts. $1^{\circ}$ ao 12. In: Machado, A. C. C. (org.), \& Zainaghi, D. S. (coord.). CLT interpretada: artigos por artigos, parágrafo por parágrafo ( $4^{\mathrm{a}}$ ed.). Barueri: Manole.

Instrução Normativa da Receita Federal do Brasil n 971, de 13 de novembro de 2009. (2009). Dispõe sobre normas gerais de tributação previdenciária e de arrecadação das contribuições sociais destinadas à Previdência Social e as destinadas a outras entidades ou fundos, administradas pela Secretaria da Receita Federal do Brasil (RFB). Brasília, DF, Brasil. Recuperado em 10 jun. de 2016, de http://normas.receita.fazenda.gov.br/sijut2consulta/ link.action?idAto $=15937 \&$ 
Julião, D., Cortês, F., Farias, J. M. S., Lohman, J., \& Silva, T. C. (2009). A influência das leis trabalhistas brasileiras na relação capital/trabalho dos guias de turismo. Observatório de Inovação do Turismo: revista acadêmica. IV(3), 1-19.

Lei $\mathrm{n}^{\circ}$ 6.505, de 13 de dezembro de 1977. (1977). Dispõe sobre as atividades e serviços turísticos; estabelece condições para o seu funcionamento e fiscalização; altera a redação do artigo 18, do Decreto-lei $n^{\circ}$ 1.439, de 30 de dezembro de 1975; e dá outras providências. Brasília, DF, Brasil. Recuperado em 01 mar. 2016, de http://www.planalto.gov.br/ccivil_03/ leis/1970-1979/L6505.htm

Lei no 8.181 de 28 de março de 1991. (1991). Dá nova denominação à Empresa Brasileira de Turismo (EMBRATUR), e dá outras providências. Brasília, DF, Brasil. Recuperado em 01 mar. 2016, de http://www.planalto.gov.br/ccivil_03/leis/L8181.htm

Lei no 8.212, de 24 de julho de 1991. (1991). Dispõe sobre a organização da Seguridade Social, institui Plano de Custeio, e dá outras providências. Brasília, DF, Brasil. Recuperado em 10 de jun. 2016, de http://www.planalto.gov.br/ccivil_03/leis/L8212cons.htm

Lei $n^{\circ}$ 8.623, de 28 de janeiro de 1993. (1993). Dispõe sobre a profissão de Guia de Turismo e dá outras providências. Brasília, DF, Brasil. Recuperado em 01 mar. 2016, de http://www. planalto.gov.br/ccivil_03/leis/L8623.htm

Lei n 5.240, de 08 de janeiro de 1998. (1998). Dispõe sobre atividades turísticas no município de Florianópolis. Florianópolis, SC, Brasil. Recuperado em 01 mar. 2016, de https://www. legisweb.com.br/legislacao/?id=174604.

Lei $\mathrm{n}^{\circ}$ 10.406, de 10 de janeiro de 2002. (2002). Institui o Código Civil. Brasilia, DF, Brasil Recuperado em 01 mar. 2016, de http://www.planalto.gov.br/ccivil_03/leis/2002/L10406.htm

Lei $n^{\circ} 6.943$, de 12 de junho de 2008. (2008). Dispõe sobre a regulamentação do exercício da profissão de guias de turismo no estado de Alagoas. Maceió, AL, Brasil. Recuperado em 01 mar. 2016, de http://www.gabinetecivil.al.gov.br/legislacao/leis/leis-ordinarias/2008/test53

Lei n` 11.771, de 17 de setembro de 2008. (2008). Dispõe sobre a Política Nacional de Turismo, define as atribuições do Governo Federal no planejamento, desenvolvimento e estímulo ao setor turístico; revoga a Lei no 6.505, de 13 de dezembro de 1977, o Decreto-Lei no 2.294, de 21 de novembro de 1986, e dispositivos da Lei no 8.181, de 28 de março de 1991; e dá outras providências. Brasília, DF, Brasil. Recuperado em 01 mar. 2015, de http://www.planalto.gov. br/ccivil_03/_ato2007-2010/2008/lei/l11771.htm

Lei $n^{\circ}$ 12.933, de 09 de janeiro de 2014. (2014). Institui a Política Estadual de Turismo, o Sistema Estadual de Turismo, e dá outras providências. Salvador, BA, Brasil. Recuperado em 01 mar. 2016, de http://bahia.com.br/wp-content/uploads/2014/01/LEI-do-TURISMO.pdf 
Lei $\quad n^{\circ} 12.974$, de 15 de maio de 2014. (2014). Dispõe sobre as atividades das Agências de Turismo. Brasília, DF, Brasil. Recuperado em 01 mar. 2016, de http://www.planalto.gov.br/ ccivil_03/_Ato2011-2014/2014/Lei/L12974.htm

Lei complementar $n^{\circ} 128$, de 19 de dezembro de 2008. (2008). Altera a Lei Complementar no 123, de 14 de dezembro de 2006, altera as Leis nos 8.212, de 24 de julho de 1991, 8.213, de 24 de julho de 1991, 10.406, de 10 de janeiro de 2002 - Código Civil, 8.029, de 12 de abril de 1990, e dá outras providências. Brasília, DF, Brasil. Recuperado em 01 mar. 2016, de http:// www.planalto.gov.br/ccivil_03/leis/LCP/Lcp128.htm

Lenza, P. (2012). Direito constitucional esquematizado (16ª ed.). São Paulo: Saraiva.

Martins, S. P. (2010). Trabalhador autônomo. In: Martins, S. P., \& Messa, A. F. (coord.). Empresa e trabalho: estudos em homenagem a Amador Paes de Almeida. São Paulo: Saraiva.

Merçon, P. G. A. (2005). Relação de trabalho - contramão dos serviços de consumo. Revista Tribunal Regional do Trabalho $3^{a}$ Região. 42(72), 113-128. Recuperado em 01 mar. 2016, de http://www.trt3.jus.br/escola/download/revista/rev_72/Paulo_Mercon.pdf

Mota, F. A. (2012). O ordenamento jurídico brasileiro: considerações críticas à sua integralidade sistêmica. Scientia, 1(2), 192-395.

MTE. (2010). Classificação brasileira de ocupações: CBO - 2010 (3ª ed. v. 1). Brasília, DF: MTE, SPPE.

Oliveira, S. R., \& Piccinini, V. C. (2011). Mercado de trabalho: (des)entendimentos. Revista de Administração Pública, 45(5), 1517-1538.

Paulo, V., \& Alexandrino, M. (2008). Direito constitucional descomplicado (3a ed.). São Paulo: MÉTODO.

Portaria MTur no 130, de 26 de julho de 2011. (2011). Institui o Cadastro dos Prestadores de Serviços Turísticos - Cadastur, o Comitê Consultivo do Cadastur - CCCad e dá outras providências. Brasília, DF, Brasil. Recuperado em 01 mar. 2016, de http://www.normaslegais. com.br/legislacao/portariamtur130_2011.htm

Portaria MTur no 27, de 30 de janeiro de 2014. (2014). Estabelece requisitos e critérios para o exercício da atividade de Guia de Turismo e dá outras providências. Brasília, DF, Brasil. Recuperado em 01 mar. 2016, de http://www.turismo.gov.br/turismo/legislacao/ portarias/20140131.html

Poletti, R. (2010). Introdução ao direito (4ª ed.). São Paulo: Saraiva.

Reglamento de la Ley General de Turismo, 06 de julio de 2015. (2015). Reglamento de la Ley General de Turismo, México, DF, México. Recuperado em 01 mar. 2016, de http://www. diputados.gob.mx/LeyesBiblio/regley/Reg_LGT.pdf 
Resolução Normativa no 04, de 28 de janeiro de 1983. (1983). Brasília, DF, Brasil. Recuperado em 01 mar. 2016, de http://www.portaleducacao.com.br/turismo-e-hotelaria/artigos/4279/ resolucao-normativa-cntur-n-04-de-28-de-janeiro-de-1983

Rodrigues, F. D. (2013). Arts. 579 a 652. In: Machado, A. C. C. (org.), Chinellato, S. J. (coord.). Código Civil interpretado: artigo por artigo, parágrafo por parágrafo (6ª ed.). Barueri: Manole. Saraiva, R. (2006). Direito do Trabalho para concursos públicos (4ª ed.). São Paulo: Método.

Schmidt, C. J. (1979). The guided tour: insulated adventure. Urban Life, 7(4), 441-467.

SINDEGTUR/RJ. (2016). Piso de remuneração por serviço (PRS 2017). Recuperado em 10 de jun. 2016, de http://sindegtur.org.br/2010/prs2017.pdf

SINGTUR/FOZ. (2016). Convenção Coletiva de Trabalho. Recuperado em 10 de jun. 2016, de http://singturfoz.com.br/convencao_coletiva.html

SITRATUH/Florianópolis. (2016). Convenção Coletiva de Trabalho. Recuperado em 10 de jun. 2016, de http://www.sitratuh.org.br/convencoes.html

Silva, M. L., \& Rezende, M. E. T. (2016). Rotinas trabalhistas: legislação e práticas para gestão de pessoas ( $2^{\mathrm{a}}$ ed.). São Paulo: Érica.

Tavares, A. R. (2016). Curso de direito constitucional (14ª ed. rev. e atual.). São Paulo: Saraiva.

Telles Junior, G. (2008). Iniciação na ciência do direito (4ª ed.). São Paulo: Saraiva

The Singapore Tourism Board (Amendment) Act 2014, of march 17, 2014. (2014). Singapura. Recuperado em 01 mar. 2016, de http://statutes.agc.gov.sg

Trigo, L. G. G. (2009). Turismo básico (8ª ed.). São Paulo: SENAC São Paulo.

UNWTO. (2016). World Tourism Organization. Recuperado em 10 jan. 2016, de http://www2.unwto.org

Valle, I. A. (2004). A profissão de guia de turismo: conhecendo o passado e o presente para projetar o futuro. Dissertação de mestrado, Universidade Estadual de Santa Cruz/Universidade Federal da Bahia, Ilhéus, BA, Brasil.

WFTGA. (2016). World Federation of Tourist Guide Associations. Recuperado em 01 mar. 2016, de http://www.wftga.org

Zugman, F. (2012). Empreendedores esquecidos: um guia para médicos, advogados, contadores, arquitetos, psicólogos e outros profissionais administrarem melhor sua prática. Rio de Janeiro: Elsevier. 
Contribuição dos autores na construção do trabalho:

Zettermann: Concepção do estudo, coleta de dados, análise dos dados e redação do artigo, revisão crítica do conteúdo e aprovação da versão final. Vergara: Redação, revisão crítica do conteúdo e aprovação da versão final. 